\title{
Mycological studies as a tool to improve the control of building materials biodeterioration
}

\author{
Erasmo Gámez-Espinosa $^{\text {a, *, Natalia Bellotti }}{ }^{\mathrm{a}, \mathrm{b}}$, Cecilia Deyá ${ }^{\mathrm{a}, \mathrm{c}}$, Marta Cabello $^{\mathrm{b}, \mathrm{d}}$ \\ ${ }^{a}$ Centro de Investigación y Desarrollo en Tecnología de Pinturas (CONICET-CICBA-Ing.-UNLP), Buenos Aires, Argentina \\ ${ }^{\mathrm{b}}$ Facultad de Ciencias Naturales y Museo, Universidad Nacional de La Plata, Buenos Aires, Argentina \\ ${ }^{\mathrm{c}}$ Facultad de Ingeniería, Universidad Nacional de La Plata, Buenos Aires, Argentina \\ dinstituto de Botánica “Carlos Spegazzini”(CICPBA-UNLP), Argentina
}

\section{A R T I C L E I N F O}

\section{Keywords:}

Building materials

Biodeterioration

Filamentous fungi

\begin{abstract}
A B S T R A C T
Fungal deterioration of building materials causes economic losses due to restoration processes and because it affects the health of the people exposed. Therefore, it is necessary to obtain highly deteriorating fungal strains to carry out studies focused on biodeterioration control. The aim of this research was to study the mycobiota involved in deterioration of facades through the isolation and characterization of fungal strains. In this sense, this paper characterizes the mycobiota that contributes to the deterioration of brick and concrete present in those places. Samples were taken from bricks and concrete with visible biodeterioration of the Cathedral of La Plata and the Experimental Station of the Centro de Investigación y Desarrollo en Tecnología de Pinturas. Relative density, apparition relative frequency, and ecological category of fungi isolates were determined. The deteriorating attributes were determined by carbonate dissolution test, pigment secretion assay, acid production test and brick weight variation. Cladosporium sp., Penicillium sp. and Aspergillus sp. were the taxa with the highest apparition relative frequency and abundance. Aspergillus niger MN371276, Lasiodiplodia theobromae MN371283, Cladosporium sphaerospermum MN371394, Penicillium commune MN371392 and Arthothelium spectabile MT071822 were the strains with the highest biodeteriorant activity. These strains can be used in studies on biodeterioration control of buildings materials.
\end{abstract}

\section{Introduction}

Fungi are ubiquitous heterotrophic organisms able to endure extreme environmental conditions and to adopt several structural, morphological and metabolic strategies to survive [1]. Filamentous fungi are frequently described as deterioration agents of building materials in both indoor and outdoor environments [2,3]. In the built environment, filamentous fungi are associated with physical and aesthetic damages and human health issues such as allergies and toxic reactions. Related problems such as asthma, cough, wheezing, and upper respiratory infections are also described [4]. Fungi are microorganisms with increased survival capacity on surfaces with low water content and can tolerate intense ultraviolet radiation. Solid substrates exposed outdoors are subject to weathering and also to biological growth on their surfaces, which causes undesirable alterations known as biodeterioration [5,6]. The main biological damage is caused by aesthetic biodeterioration due to the production of organic pigments and coverage of the surface by colored biofilms; physical biodeterioration resulting from mechanical forces produced by mycelium within pores that cause the material breakup, and chemical biodeterioration due to the direct action of the metabolic products excreted $[7,8]$.

The spoilage of structural materials by filamentous fungi causes negative effects on the preservation of historic-cultural and work buildings. An important example of this is the Cathedral of the Immaculate Conception, also known as the Cathedral of La Plata (CP). The $\mathrm{CP}$ is affected by growth of lichens, green algae, cyanobacteria, mosses and higher plants $[9,10]$. However, the biodeterioration by filamentous fungi has not been studied. Regarding the biodeterioration of cultural heritage, it is necessary to evaluate levels of fungal contamination in urban monuments and fungi resistance to certain materials or conservation treatments [11].

In work buildings, it is also important to monitor the deterioration of structural materials by fungi, since they can cause indoor and outdoor air pollution. The mycobiota of indoor environments contains about 150

\footnotetext{
* Corresponding author.

E-mail addresses: e.gamez@cidepint.ing.unlp.edu.ar (E. Gámez-Espinosa),n.bellotti@cidepint.ing.unlp.edu.ar (N. Bellotti).
} 
species and it is considered that $1000 \mathrm{CFU} / \mathrm{m}^{-3}$ is a high level of exposure for an indoor occupant of a building [12]. The fungal genera most frequently found in indoor environments are Cladosporium, Penicillium, Aspergillus, and Stachybotrys [13].

The aim of this research was to study the mycobiota involved in deterioration of facades through the isolation and characterization of fungal strains. First, the present research work was focused on the study of the mycobiota involved in the deterioration of brick and concrete in facades by the determination of relative density, apparition relative frequency and ecological category of the fungal isolates. Then, the other goal was to assess the most deteriorating isolated strains by different tests such as calcium carbonate dissolution test, acid production test, pigment secretion assay and brick weight variation in humidity chamber. Molecular analysis of the most deteriorating fungal strains was performed. These strains will be used in further research to study new bioactive materials in the control of building biodeterioration.

\section{Materials and methods}

\subsection{Sampling sites and fungal isolation}

Microbiological sampling was carried out during October 2017 (spring time) at the Cathedral of La Plata (CP) $\left(34^{\circ} 55^{\prime} \mathrm{S}, 57^{\circ} 57^{\prime} \mathrm{O}\right)$ and at the Centro de Investigación y Desarrollo en Tecnología de Pinturas

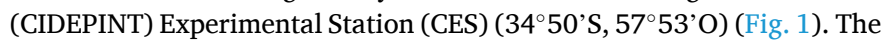
$\mathrm{CP}$ is the main Catholic temple in La Plata city (capital of Buenos Aires province), Argentina and one of the largest churches in the world. It is a neogothic building with an area of $7000 \mathrm{~m}^{2}$ built with exposed brick and mortar, giving it a very special characteristic appearance. White cement mortar was used in the pinnacles and supporting arches of the vaults and ornaments. CIDEPINT is a center dedicated to obtaining new technological developments related to paints and protective coatings. It has an outdoor experimental station where natural service tests are carried out.

Samples were taken using the swab technique from bricks and concrete with significant biodeterioration at 0.5 and $1.5 \mathrm{~m}$ high with respect to the ground $[10,13]$. Subsequently, the swabs were introduced into tubes containing sterile physiological solution $(0.85 \mathrm{~g}$ of $\mathrm{NaCl}$ (Anedra, Argentina) $/ 100 \mathrm{~mL}$ of sterile distilled water). Serial dilutions

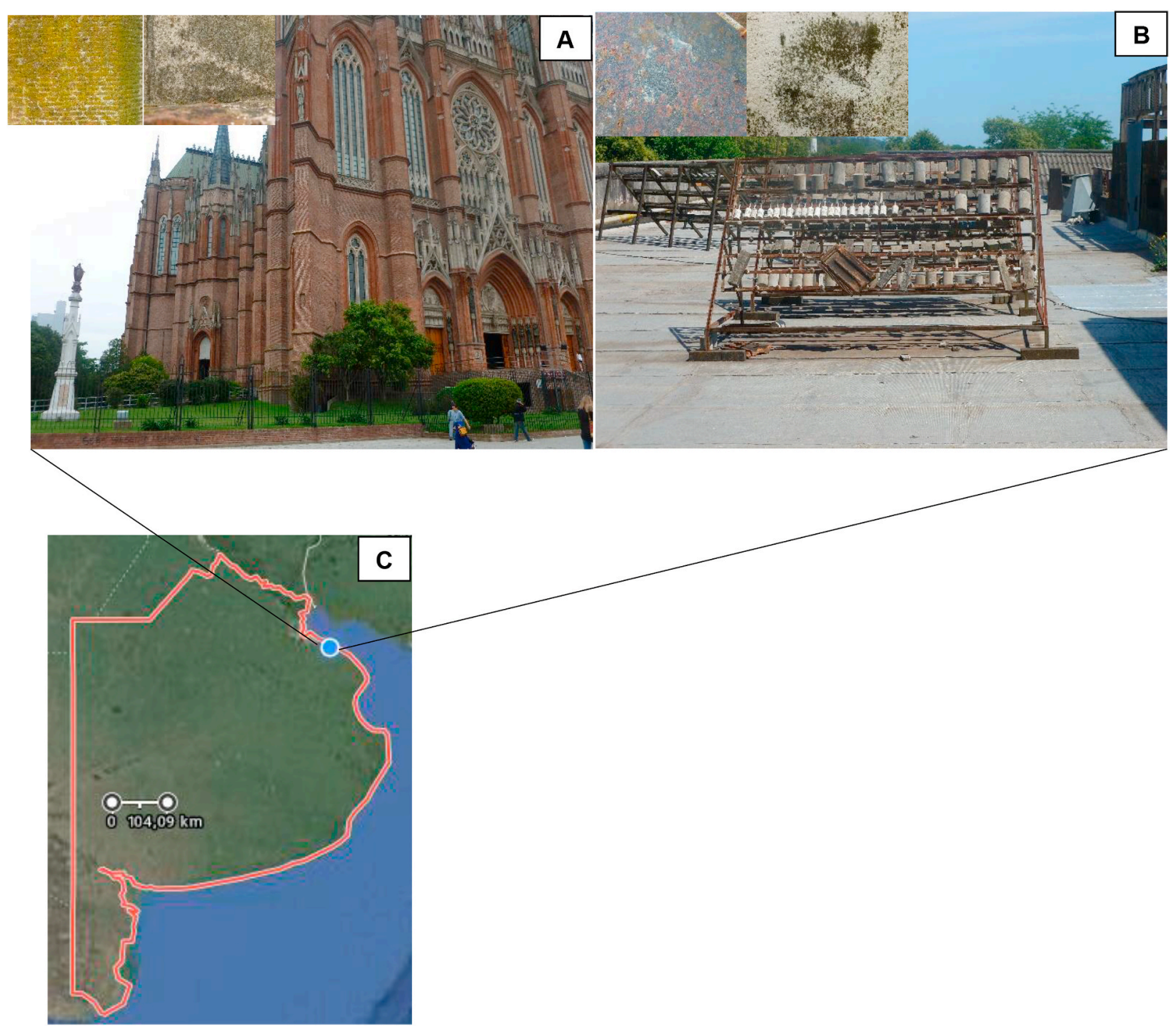

Fig. 1. Mycological sampling sites. A: Cathedral of La Plata. B: Experimental Station of the Centro de Investigación y Desarrollo en Tecnología de Pinturas. Biodeteriorated facades details. C: Highlighted in red Buenos Aires Province, taken from Google maps. (For interpretation of the references to color in this figure legend, the reader is referred to the Web version of this article.) 
(1:10-1:1000) were carried out, and $0.1 \mathrm{~mL}$ of the solution was inoculated on Petri dishes with Potato Glucose Agar (Britania, Argentina), streptomycin ( $30 \mathrm{mg} / 100 \mathrm{~mL}$ ) and Rose Bengal (Cicarelli, Argentina) (5 $\mathrm{mg} / 100 \mathrm{~mL}$ ). The plates were maintained at $28{ }^{\circ} \mathrm{C}$ for 15 days and, after close observation, filamentous fungi were isolated at 2, 7 and 15 days following conventional microbiological techniques.

\subsection{Taxonomic identification and ecological category of isolates}

For the taxonomic analyses, all strains were grown on Potato Dextrose Agar (Britania, Argentina) and $39 \mathrm{~g}$ of distilled water per liter were used. The isolates were identified to the lowest possible taxon based on their reproductive, somatic structures and colony cultural characteristics using standard taxonomic keys $[14,15]$. In some cases, the microculture technique was used. In others, parts of mycelium were taken from mature colonies and observed under light microscope. In order to better observe the conidiophores alcohol was added to the highly sporulated preparations.

Relative density (RD) [16] and apparition relative frequency (RF) were calculated using formula (1) and formula (2), respectively:

$\mathrm{RD}(\%)=\frac{\text { number of colonies of the taxon }}{\text { total number of colonies of taxa }} \times 100$

where $\mathrm{a}$ is Number of colonies of the taxon, $\mathrm{b}$ is Total of colonies of taxa

$\mathrm{RF}(\%)=\frac{\text { number of times a taxon is detected }}{\text { total number of samplings realised }} \times 100$

where $\mathrm{c}$ is Times a taxon is detected, $\mathrm{d}$ is Total number of sampling realized.

From RF values of the fungi, the following ecological categories were given: abundant (81-100\%); common (61-80\%); moderate (41-60\%); occasional (21-40\%); and rare (0.1-20\%), taking into account what was proposed by Esquivel et al. [17].

\subsection{Biodeterioration assays}

\subsubsection{Inoculum preparation}

The spore suspension was carried out from mature colonies. First, physiological solution ( $0.85 \mathrm{~g}$ of $\mathrm{NaCl} / 100 \mathrm{~mL}$ of sterile $\mathrm{DW}$ ) was added to the colonies and finally, it was carefully removed by inoculation loop so as not to drag mycelium. The inoculum concentration was adjusted to $10^{5}$ spores/mL employing a Neubauer chamber.

\subsubsection{Calcium carbonate (calcite) dissolution test}

The procedure followed was similar to that proposed by Unkovic et al. [18]. The potential ability of the tested fungi to degrade calcite was screened using Petri dishes with culture medium of the following composition, per liter of distilled water: $5 \mathrm{~g}$ of calcium carbonate (Anedra, Argentina); $30 \mathrm{~g}$ of malt extract (Circe, Argentina); $3 \mathrm{~g}$ of mycological peptone (Oxoid, United Kingdom), and $15 \mathrm{~g}$ agar (Parafarm, Argentina). The Petri dishes with $\mathrm{CaCO}_{3}$ malt extract agar were inoculated with agarized $6 \mathrm{~mm}$ diameter mycelium disc and incubated for 14 days at $28{ }^{\circ} \mathrm{C}$. Positive strains displayed a clear zone around the colony, thus confirming calcium carbonate dissolution. The test was performed in triplicate.

\subsubsection{Acid production test}

The strains that resulted positive to the carbonate dissolution test were selected to perform the acid production test. To determine the capacity of fungi affecting the $\mathrm{pH}$ value of the substrate on which they grow, isolates were cultivated in a Liquid Minimal Medium (LMM) supplemented with glucose $1 \%$ and phenol red $0.001 \%$ of the following composition, per liter of distilled water: sodium nitrate, $2 \mathrm{~g}$; potassium phosphate, $1 \mathrm{~g}$; magnesium sulfate, $0.5 \mathrm{~g}$; ferrous sulfate, $0.01 \mathrm{~g}$ and potassium chloride, $0.5 \mathrm{~g}$. The brand of the previous reagents was
Anedra, Argentina with the exception of potassium chloride (Cicarelli, Argentina). Before adding the inoculum, the $\mathrm{pH}$ was adjusted to 7 and the control was test tubes with spore-free liquid medium. Test tubes with phenol red LMM were inoculated with a spore solution $\left(10^{5}\right.$ spores $\left./ \mathrm{mL}\right)$ and incubated for 3 days at $28^{\circ} \mathrm{C}$ when phenol red $\mathrm{pH}$-indicator showed a change in color [19]. The test was performed in triplicate.

\subsubsection{Pigment secretion}

The potential ability of the isolates to secrete organic pigments under nutrient-limited conditions (present on the surface of structural materials), and consequently to induce alterations in the original coloration was screened using Petri dishes with culture medium similar to those used in the calcium carbonate dissolution test. The Petri dishes were incubated for 7 days at $28{ }^{\circ} \mathrm{C}$. Secretion of fungal pigments was confirmed by changes in color of medium through direct observation. The assay was performed in triplicate.

\subsubsection{Exposure studies in humidity chamber}

The test was carried out according to the procedure of George et al. [20]. The criteria used to select the strains in this assay were the capacity to secrete pigments and the high growth speed. Bricks of $19 \pm 1.0 \mathrm{~cm}^{3}$ were introduced in Petri dishes, each one was inoculated with $200 \mu \mathrm{L}$ of spore solution $\left(10^{5}\right.$ spores $\left./ \mathrm{mL}\right)$. Two sets of three bricks were inoculated by each of the strains studied in order to remove the panels after 6 and 12 months. The brick samples were placed in a Humidity chamber at $100 \%$ relative humidity. Room temperature of $25{ }^{\circ} \mathrm{C}$ was maintained inside the chamber. After removal, the bricks were weighted with and without biofilm.

For the fungal biofilm elimination, the bricks were immersed in sodium hypochlorite (10\%) solution and dried to constant weight at $60^{\circ} \mathrm{C}$. Control bricks without inoculation were used.

The weight loss was calculated from:

$\mathrm{Dw}=\mathrm{W}_{1}-\mathrm{W}_{2}$

where $\mathrm{W} 1$ is the weight of the brick before introducing it into the chamber and W2 the weight after treatment with sodium hypochlorite.

After one year, the bricks that lost the most weight were observed by scanning electron microscopy (Philips FEI Quanta 200) and the working condition was high vacuum $\left(10^{-6}\right.$ torr $)$.

\subsection{Molecular analysis of the most deteriorating fungal strains}

Taxonomic identification was confirmed by molecular methods based on the analysis of sequences coding for ITS (internal transcribed spacer) rRNA region only in the most deteriorating fungal isolates. The ITS sequences were amplified through PCR (polymerase chain reaction) and then, they were sequenced and analyzed [21]. The primers used were ITS1 (5'-TCC GAT GGT GAA CCT GCG G-3') and ITS4 (5'-TCC TCC GCT TAT TGA TAT GC-3') [22,23]. This procedure was carried out by Macrogen (www.macrogenlatam.com.ar). The sequences obtained were analyzed by means of the genetic data bank (www.ncbi.nlm.nih.gov/b last/Blast.cgi) using a search and sequence analysis software to find the closest known analogues with $99 \%$ similarity values. In addition, evolutionary history was inferred using the Unweighted Pair Group Method using Arithmetic Averages (UPGMA). This tree-making method assumes that the rate of evolution has remained constant throughout the evolutionary history of the included taxa [24]. The evolutionary distances were computed using the p-distance method and were in the units of the number of base differences per site. This analysis involved 5 nucleotide sequences. Codon positions included were $1 \mathrm{st}+2 \mathrm{nd}+3 \mathrm{rd}+$ Noncoding. All ambiguous positions were removed for each sequence pair (pairwise deletion option). Evolutionary analyses were conducted in MEGA 10.0.5® [25]. 


\subsection{Statistical analysis}

Statistical Analysis of brick weight variation was performed with the RStudio 1.1.463 ${ }^{\circledR}$ program. All assays were performed in triplicate and the probability distribution was analyzed by Normal distribution test. A two-way ANOVA analysis was performed. The included factors were time and treatment. The former had two levels: 6 and 12 months and the latter had 8 levels, which is the number of strains tested. Then, Tukey test was applied. Both tests were applied using the multcomp package. Similarly, this program was used to analyze the association between certain variables and the mycobiota present in the sampling sites using Principal Component Analysis (PCA). Specifically for these analysis packages, MASS, ggplot2, scales and factoextra were used.

\section{Results and discussion}

\subsection{Fungal isolation and ecological category}

The swab technique and conventional microbiological techniques allowed the isolation and identification of 43 filamentous fungi. Table 1 presents a list of the isolates belonging to phyla Mucoromycota,
Ascomycota or Basidiomycota. These fungal isolates were recorded for the first time on brick and concrete in $\mathrm{CP}$ and CES. Fig. 2 presents the RD and the RF from CP and CES. In Fig. 2A, it can be seen that the genera with the highest relative frequency in $\mathrm{CP}$ were Cladosporium sp., Penicillium sp. and Aspergillus sp. and together with Alternaria alternata were considered abundant. On the other hand, the appearance of Epicoccum nigrum, Arthothelium spectabile and Lasiodiplodia theobromae was common in these materials. However, in CES the fungal isolates were classified as abundant, common, moderate and occasional (Fig. 2B). In this sampling place, DUSM 1 and Chrysonilia sp. were the strains with the highest relative frequency. In addition, YUSM (yellow unsporulated septate mycelium) and C. cladosporioides presented the highest relative density in CP and CES, respectively. Similar fungal strains were reported by Mallo et al. [26] for the city of La Plata in a study related to the presence of airborne fungi detected by various sampling methods. At the same time, Negrin et al. [27] reported that Cladosporium sp. was predominant in all the samples collected, followed by genera Alternaria, Penicillium, Aspergillus and Epicoccum in bioaerosols in La Plata. In the same way, filamentous fungi were reported in a study that evaluated the development of bioincrustations on marble and mortar surfaces of several historically and architecturally valuable crypts at the cemetery

Table 1

Pigment secretion and carbonate dissolution of fungi isolated from CP and CES. The isolates are ordered by the place of sampling.

\begin{tabular}{|c|c|c|c|c|c|c|}
\hline No. & Fungal Isolate & Sample place & Structural material & Height (m) & Carbonate dissolution & Pigment secretion \\
\hline 1 & Penicillium sp. Link 1 & $\mathrm{CP}$ & Brick & 1.5 & + & - \\
\hline 2 & Epicoccum nigrum Link. & $\mathrm{CP}$ & Brick & 1.5 & - & + \\
\hline 3 & Cladosporium sp. Link 1 & $\mathrm{CP}$ & Brick & 1.5 & - & - \\
\hline 4 & Cladosporium sp. Link 2 & $\mathrm{CP}$ & Brick & 1.5 & - & - \\
\hline 5 & Alternaria alternata (Fr.) Keissl. & $\mathrm{CP}$ & Brick & 1.5 & - & - \\
\hline 6 & Cladosporium sp. Link 3 & $\mathrm{CP}$ & Brick & 1.5 & - & - \\
\hline 7 & Penicillium sp. Link 2 & $\mathrm{CP}$ & Brick & 0.5 & + & - \\
\hline 8 & Cladosporium sp. Link 4 & $\mathrm{CP}$ & Brick & 0.5 & - & - \\
\hline 9 & Coelomycetes Grove. 1 & $\mathrm{CP}$ & Brick & 0.5 & - & - \\
\hline 10 & Cladosporium sp. Link 5 & $\mathrm{CP}$ & Brick & 0.5 & - & - \\
\hline 11 & Orbiliomycetes O.E. Erikss. \& Baral & $\mathrm{CP}$ & Brick & 1.5 & - & - \\
\hline 12 & Arthrinium sp.Kunze. 1 & $\mathrm{CP}$ & Brick & 1.5 & - & - \\
\hline 13 & Lasiodiplodia theobromae Griffon \& Maubl. & $\mathrm{CP}$ & Brick & 1.5 & - & + \\
\hline 14 & Penicillium commune Thom & $\mathrm{CP}$ & Brick & 1.5 & + & - \\
\hline 15 & Cladosporium sphaerospermum Penz. & $\mathrm{CP}$ & Brick & 0.5 & - & - \\
\hline 16 & Penicillium sp. Link 3 & $\mathrm{CP}$ & Brick & 0.5 & + & - \\
\hline 17 & Penicillium sp. Link 4 & $\mathrm{CP}$ & Brick & 0.5 & - & - \\
\hline 18 & Cladosporium sp. Link 6 & $\mathrm{CP}$ & Brick & 1.5 & - & - \\
\hline 19 & Arthrinium sp.Kunze. 2 & $\mathrm{CP}$ & Brick & 1.5 & - & - \\
\hline 20 & Penicillium sp. Link 5 & $\mathrm{CP}$ & Concrete & 0.5 & - & - \\
\hline 21 & Cladosporium cladosporioides (Fresen.) & $\mathrm{CP}$ & Concrete & 0.5 & - & - \\
\hline 22 & Coelomycetes Grove. 2 & $\mathrm{CP}$ & Concrete & 0.5 & - & - \\
\hline 23 & Penicillium sp. Link 6 & $\mathrm{CP}$ & Concrete & 0.5 & - & - \\
\hline 24 & Penicillium sp. Link 7 & $\mathrm{CP}$ & Concrete & 0.5 & - & - \\
\hline 25 & Coelomycetes Grove. 3 & $\mathrm{CP}$ & Concrete & 0.5 & - & - \\
\hline 26 & Aspergillus niger Tiegh. & $\mathrm{CP}$ & Brick and Concrete & 0.5 & + & - \\
\hline 27 & YUSM & $\mathrm{CP}$ & Concrete & 1.5 & - & + \\
\hline 28 & Arthothelium spectabile A. Massal. & $\mathrm{CP}$ & Brick & 1.5 & - & + \\
\hline 29 & Moniliella sp. Stolk \& Dakin 1 & CES & Concrete & 0.5 & - & - \\
\hline 30 & DUSM 1 & CES & Concrete & 1.5 & - & - \\
\hline 31 & DUSM 2 & CES & Brick & 0.5 & - & - \\
\hline 32 & Cladosporium cladosporioides (Fresen.) & CES & Brick & 0.5 & - & - \\
\hline 33 & DUSM 3 & CES & Concrete & 0.5 & - & - \\
\hline 34 & Moniliella sp. Stolk \& Dakin 2 & CES & Concrete & 0.5 & - & - \\
\hline 35 & Chrysonilia sp. Arx. & CES & Concrete & 1.5 & - & - \\
\hline 36 & DUSM 4 & CES & Brick & 1.5 & - & - \\
\hline 37 & Alternaria sp. Nees, 1 & CES & Concrete & 1.5 & - & - \\
\hline 38 & SUNEM & CES & Brick & 1.5 & - & - \\
\hline 39 & Moniliella sp. Stolk \& Dakin 3 & CES & Concrete & 0.5 & - & - \\
\hline 40 & Aureobasidium pullulans (de Bary) & CES & Concrete & 0.5 & - & - \\
\hline 41 & Geomyces sp. Traaen & CES & Concrete & 1.5 & - & - \\
\hline 42 & Mucor sp. Fresen. & CES & Concrete & 1.5 & - & - \\
\hline 43 & OUSM & CES & Concrete & 0.5 & - & + \\
\hline
\end{tabular}

+: Positive; -: Negative.

YUSM: yellow unsporulated septate mycelium.

DUSM: dematiaceous unsporulated septate mycelium.

OUSM: orange unsporulated septate mycelium.

SUNEM: salmon unsporulated non-septate mycelium. 
A

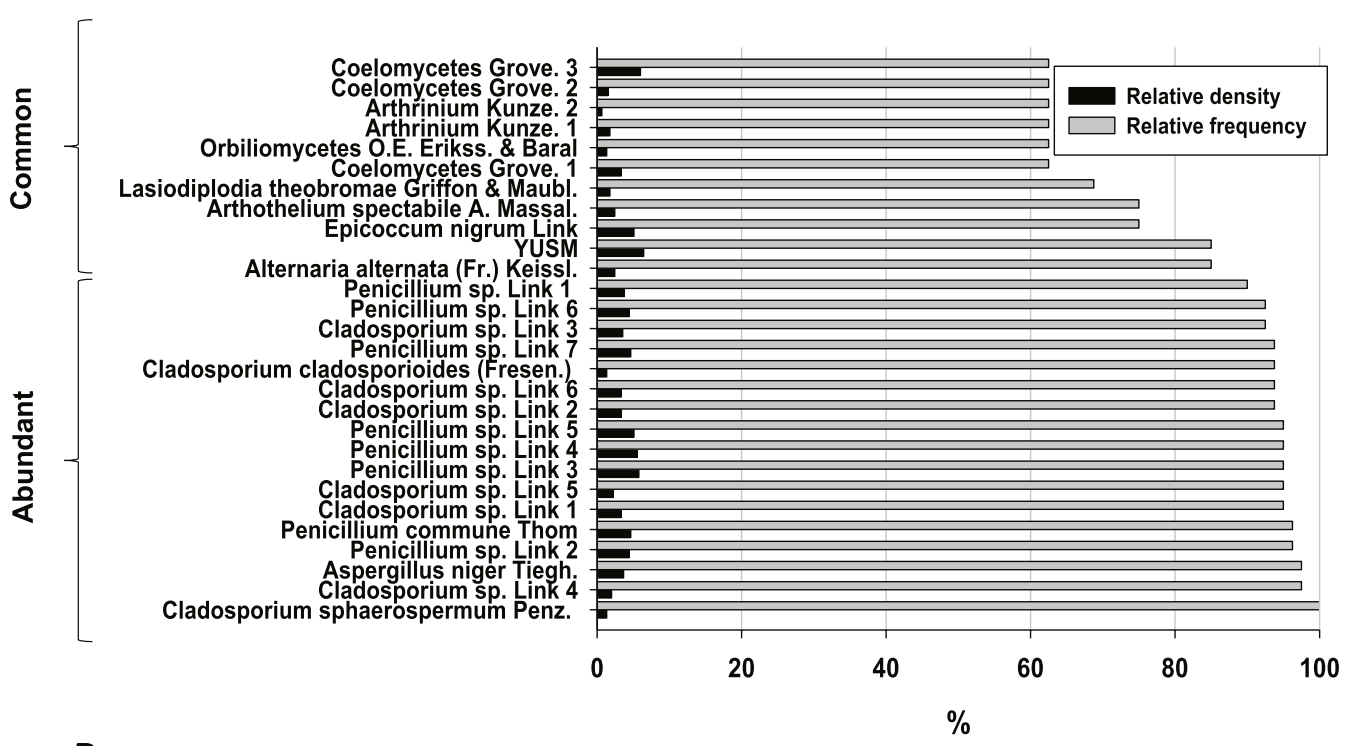

B

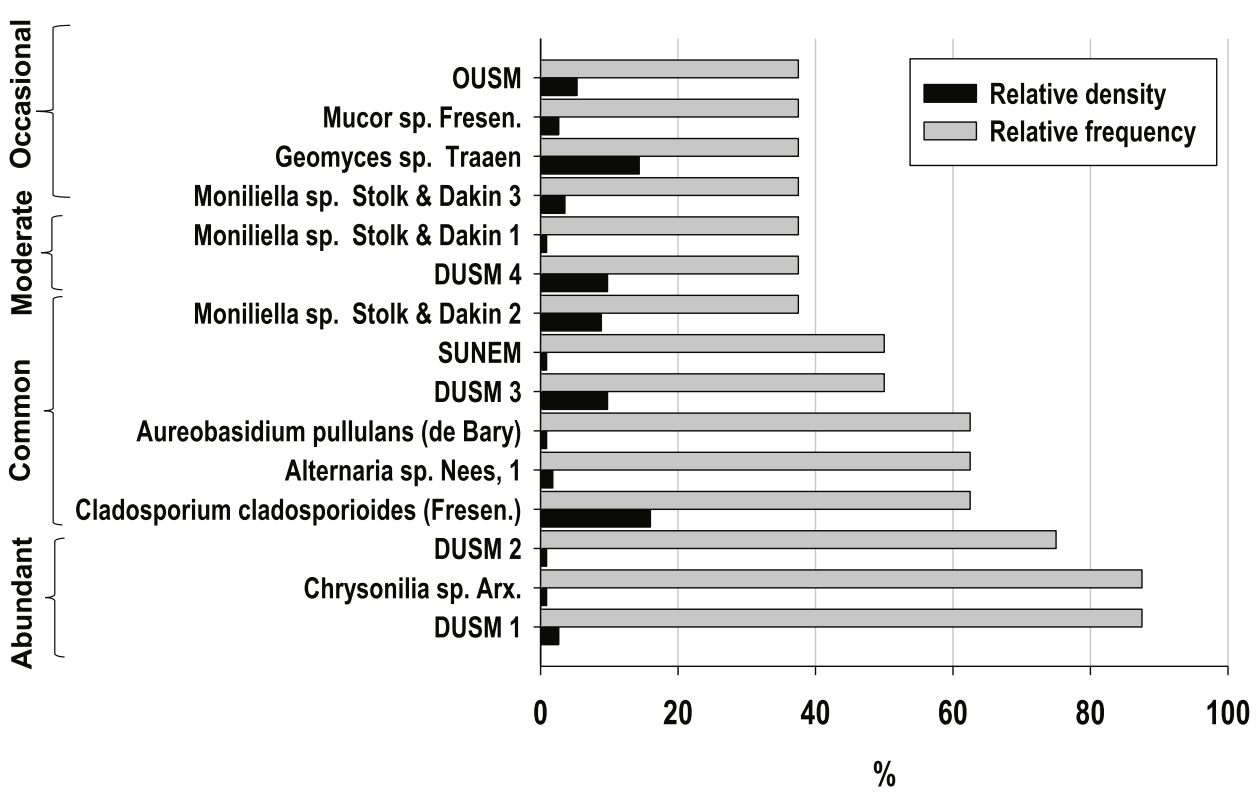

Fig. 2. Relative density, relative frequency and ecological category of isolated fungi. A: CP; B: CES.

of La Plata [28]. Some of the isolates may be potentially pathogenic for the visitors of such locations. As mentioned in the literature review, filamentous fungi are associated with human health issues such as allergies, toxic reactions and upper respiratory infections [4].

Some of these species are involved in the biodeterioration of building materials worldwide (stone, mortars, glass, marble, etc) for example, Aspergillus, Penicillium and Cladosporium [2,29,30]. In addition, L. theobromae, A. spectabile and Moniliella sp. were detected for the first time on concrete and bricks.

There are variations between the number of taxa and the ecological categories for the sampling sites (Fig. 2). These results may be due to parameters related to outdoor climate, petrochemical pollution and differences in the chemical composition of the materials. In this sense, near La Plata city there are Petrochemical Plants located approximately 2.5 and $5 \mathrm{~km}$ away from CES and CP, respectively. In a work related to petrochemical pollution [31], different pollutant levels were studied. The authors observed that the concentrations of hexane, cyclohexane, benzene, and toluene were particularly high in the industrial region. In this sense, the presence of these pollutants could influence the mycobiota found in the sampling sites, with greater impact on CES due to the higher proximity to Petrochemical Plants. On the other hand, Diulio et al. [32] reported, according to the hourly weather data obtained from the Astronomical Observatory of La Plata for 2017, that spring and fall are transition seasons, featuring warm daytime temperatures and cool nighttime temperatures. These temperatures can significantly vary, some days registering temperatures above $32{ }^{\circ} \mathrm{C}$ and below $0{ }^{\circ} \mathrm{C}$. Owing to its riverside location, the city is fairly humid, and its average monthly humidity is higher than 75\%. La Plata receives $1092 \mathrm{~mm}$ of precipitation annually, with winters being the driest months, and summer the wettest. These climatic conditions may also influence the presence of these strains at the sampling locations. For example, depending on the water activity of the material, certain species prevail. In this sense, secondary (e.g. Cladosporium, Phoma, Ulocladium and Alternaria) and tertiary (e.g. Chaetomium, Trichoderma, Auraeobasidium and Stachybotrys) colonizers 
require higher water activity to grow [33]. Taking into account the aforementioned data related to La Plata city which prove high humidity levels throughout the year, it can be seen a correlation with the results obtained since the genus Cladosporium classified as secondary colonizer was predominant in all the samples followed by other two with the same classification (Alternaria and Epicoccum). Finally, there are differences between the chemical composition of concrete and brick. Concrete is a composite material made from cement, aggregates and additives [34]. However, brick is a clayey material generally composed of iron oxide, calcium, and magnesium [7]. Thus, differences in structure and composition of the materials may also influence the abundance and relative frequency of the species at the sampling sites.

\subsection{Biodeterioration assays}

\subsubsection{Calcium carbonate dissolution test}

Table 1 shows the results of carbonate degradation test and pigment secretion assay. Only Penicillium sp. 1, Penicillium sp. 2, Penicillium commune, Penicillium sp. 3 and Aspergillus niger were the strains with capacity to degrade $\mathrm{CaCO}_{3}$, and this can be seen in Fig. 3. It is known that mainly micromycetes from Aspergillus and Penicillium genera have calcite dissolution activity [18]. It is important to take into consideration that calcite degradation depends on various factors, primarily, on available sources of carbon and nitrogen, and thus, we cannot predict the activity of isolated in vivo species [35].

\subsection{Acid production test}

The acid production test was exclusively performed on the strains that resulted positive to the carbonate dissolution test. At the end of this test, the highest decrease in the $\mathrm{pH}$ related to control tubes $\mathrm{pH}=7.13 \pm$ 0.01 ) was caused by $A$. niger followed by $P$. commune and Penicillium sp. 3 showing average pHs with standard deviation equal to $3.27 \pm 0.06$, $5.42 \pm 0.02$ and $5.85 \pm 0.07$, respectively. On the other hand, Penicillium sp. 1 and 2 presented a lower $\mathrm{pH}$ modification $(7.00 \pm 0.05)$ with no difference between them. The $\mathrm{pH}$ decrease in the inoculated MML may well be related to the secretion of organic acids by the fungi into the surrounding medium. This would be in agreement with bibliographic data that point out that the secretion of a great variety of organic acids (oxalic, oxalacetic, citric, gluconic, oxoacetic and fumaric) by different fungi makes them highly deteriorating agents for minerals and rocks [6, 36]. Organic acids manage to form complexes with calcium, aluminum, iron, manganese, silicon and magnesium ions contributing even more to the degradation of the material [28,37].

\subsection{Pigment secretion}

E. nigrum, L. theobromae, YUSM, A. spectabile and OUSM (orange unsporulated septate mycelium) showed the ability to secrete organic pigments in the assay conditions. Most of the isolates produced pigments in various shades of yellow (Fig. 4A, D and E), while red pigments were present in two cultures (Fig. 4B and C). Pigment secretion is a process related to the biology of fungi and it can increase their biodeteriogenic attributes by making them more resistant to certain environmental conditions. Possibly not related to physical or chemical material deterioration, pigment secretion is closely related to aesthetic deterioration because it can change the normal coloration of building materials. In this sense, Trovão et al. [1] showed that E. nigrum has pigmented aerial mycelium and reproductive structures and its proliferation can contribute to aesthetic alterations in cathedrals. This damage can also be caused by other dematiaceous fungi, for example L. theobromae. However, not only pigment secretion can lead to visual deterioration but also an extensive mycelium development which also causes physical-chemical deterioration. Fungal pigments protect them against many physical and chemical environmental stressors (high temperatures, DNA damage, accumulation of reactive oxygen species,
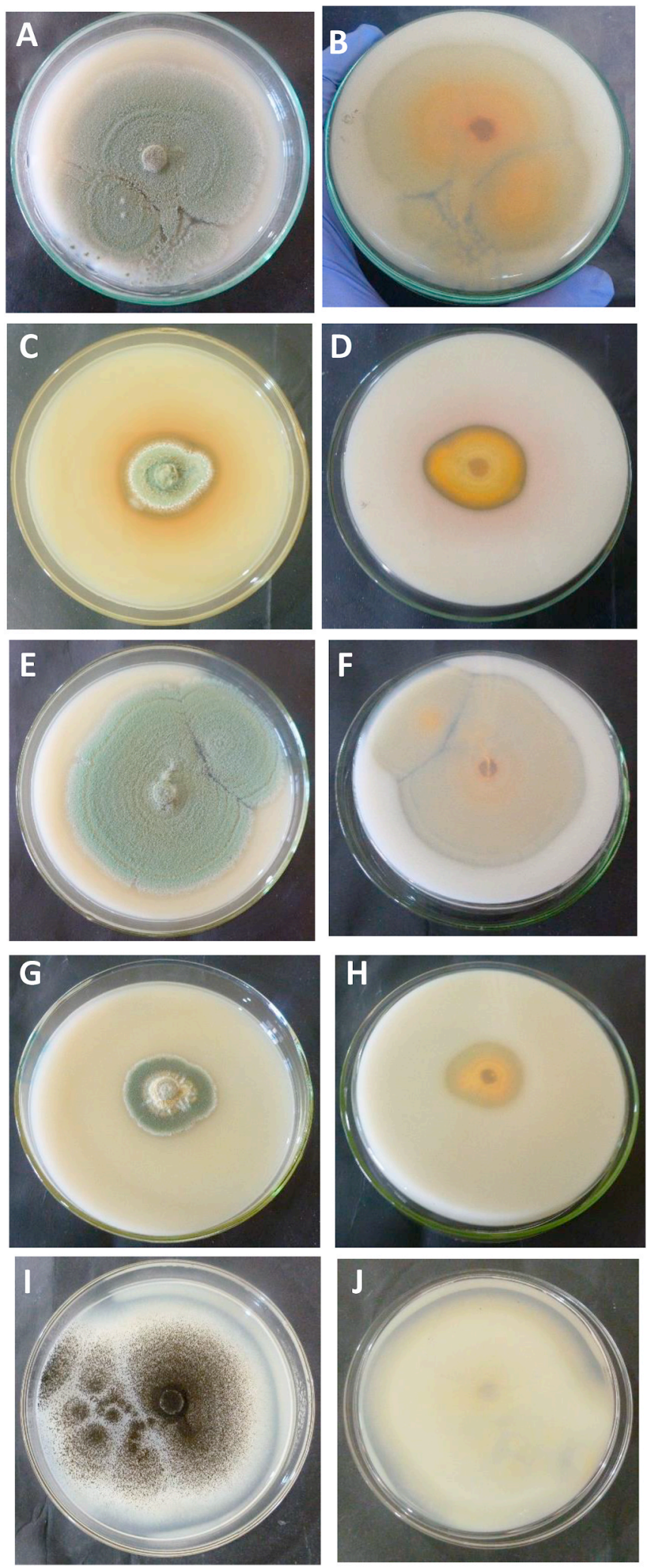

Fig. 3. Fungi with positive result in carbonate dissolution test, $t=14$ days. A and B: Penicillium sp. 1. C and D: Penicillium sp. 2. E and F: P. commune. G and H Penicillium sp. 3. I and $\mathrm{J}$ : A. niger. Colony morphology on $\mathrm{CaCO}_{3}$ malt extract agar A, C, E, G and I: Obverse; B, D, F, H and J: reverse. T $=28^{\circ} \mathrm{C}, \mathrm{t}=14$ days. 

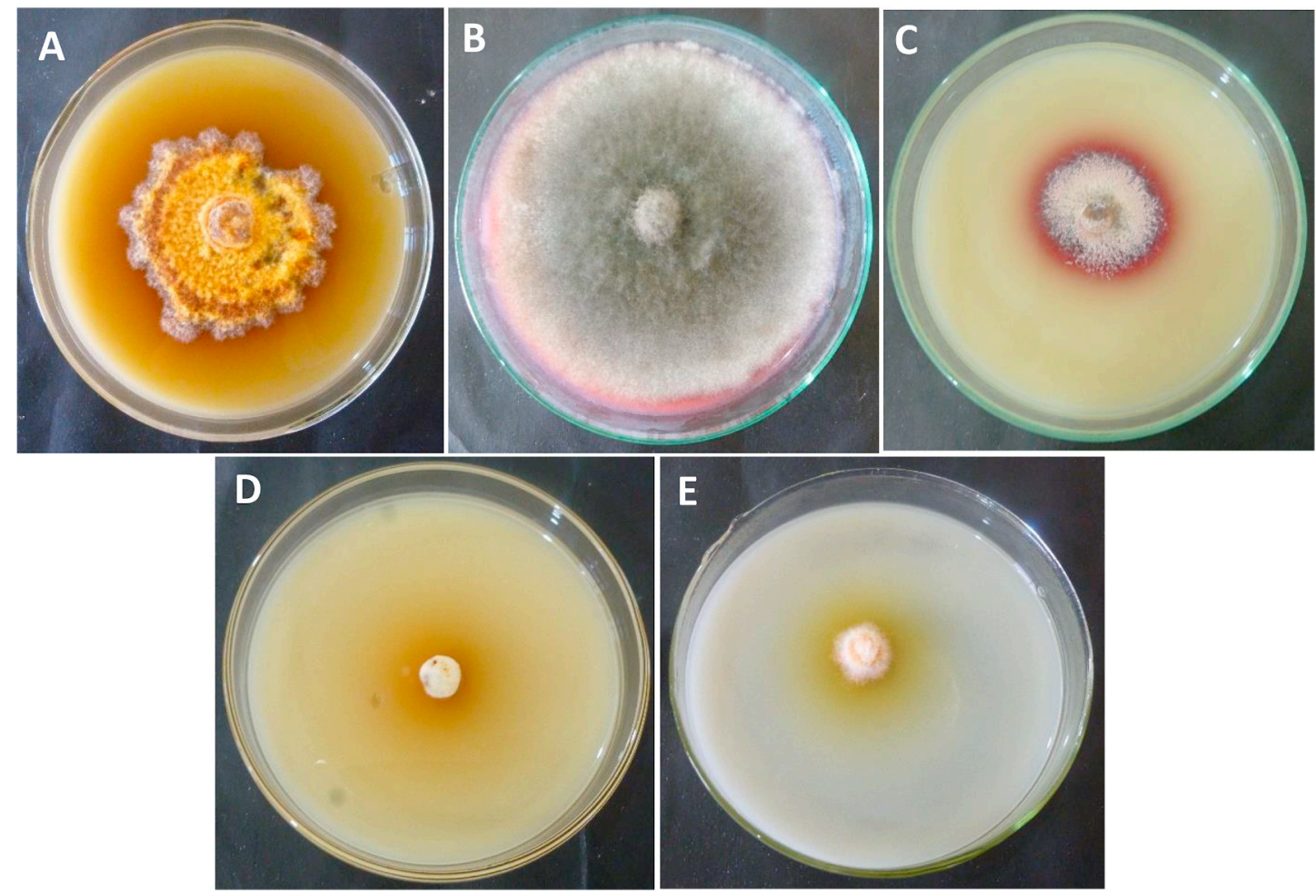

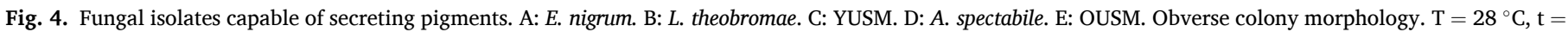
7 days.

desiccation and osmotic stresses). For example, the capture of and/or reflected radiation energy by pigments has multiple biological functions ranging from camouflage or makeup to fundamental roles in the maintenance of life including harnessing solar energy for metabolic use and protection against radiation damage [38]. Furthermore, some pigments, such as melanin, can reinforce the cell wall and increase the virulence of pathogenic fungi in plants and animals, reducing their susceptibility to biocides [39]. Another study supports the idea that pigments are then related to biofilm development. Rock-inhabiting Dothideomycetes and Eurotiomycetes have equal number of photoreceptors and the same set of protective pigments. This suggests that photoperception and regulation are important for fungi to receive nutrients through cooperation with phototrophs [36].

\subsubsection{Exposure studies in humidity chamber}

Fig. 5 shows brick samples exposed in the Humidity Chamber for 12 months where it can be seen the deterioration caused by the eight fungal isolates selected. These were selected according to their capacity to secrete pigments (E. nigrum, L. theobromae, YUSM and A. spectabile) and to their growth speed (Arthrinium sp. 1, Arthrinium sp. 2, DUSM 1 and DUSM 2). Fig. 5A-I shows stereoscopic microscope images obtained at the end of the assay (12 months). Colorless mycelium is observed on the brick surfaces under the assay conditions. Mycelial growth was more invasive in $L$. theobromae and A. spectabile, Fig. 5C and F, respectively. For this reason, SEM was applied to characterize the biofilm formed. In Fig. $5 \mathrm{~J}$, an abundant grouped conidia and vegetative mycelium of L. theobromae can be observed. Whereas in Fig. 5K, although only mycelium of $A$. spectabile was observed, the hyphae penetrated the brick pores.

In Fig. 6, it is presented a graph with the brick weight variation calculated by equation (3) and obtained from the inoculated and noninoculated (control) bricks exposed in the humidity chamber. Bricks inoculated with both $L$. theobromae and A. spectabile showed statistically significant difference $(\rho \leq 0.05)$ in weight loss with respect to the rest of the strains. It is worth noting, that the growth of both strains on the bricks caused greater weight loss at 12 months, but there were no statistically significant differences with the values recorded at 6 months. Even so, $L$. theobromae and A. spectabile presented the highest values in brick weight variation in situ. The relative humidity is an abiotic factor, which cannot only influence the growth of fungi, but it can also cause modifications in the mechanical properties of bricks [40]. For the first time, these species were found to have biodeteriorating capacity during the course of this study.

On the other hand, the association between certain variables and the mycobiota present in the sampling sites was analyzed with the PCA, whose axes explained $64 \%$ of variation using RStudio $1.1 .463 \circledR$ program. Fig. 7 showed PCA ordination of fungal isolates according to the variables analyzed. Axis 1 shows relative density, sample place, structural material, relative frequency, carbonate dissolution and acid production with $27.3 \%$ of variation. On the other hand, axis 2 shows that $20.1 \%$ corresponded to the variation of brick weight, pigment secretion and the recollection height. As a result, the strains Cladosporium sp.1, Cladosporium sp.2, A. alternata and Cladosporium sp. 3 were grouped in points $3,4,5$ and 6 , respectively. Also, the strains belonging to the genus Penicilium occurred between points 20 and 24. In this sense, the groups formed by the species can be multifactorial and may lead to similarities in taxonomy and ecology. Especially, if the variables analyzed in this study have sufficient diagnostic characters for these fungi. Thus, isolates that are in the same group can have the same growth and ecological strategies, share the same ecological niches, and use the same substrate. Similarly, Coutinho et al. [41] reported that strains belonging to the Alternaria, Cladosporium, Penicillium and Aspergillus genera were isolated on architectural ceramic material. These last two as primary colonizers of the substrate and r-strategists. On the other hand, the species of Alternaria and Cladosporium being secondary colonizers of the substrates were catalogued as K-strategists [42]. These characteristics related to the biology of the isolates may be the conditions that favor their participation in building materials biodeterioration. The hyphae can penetrate the pores of these materials and, apart from causing physical damage to the material, they can facilitate the colonization of other 

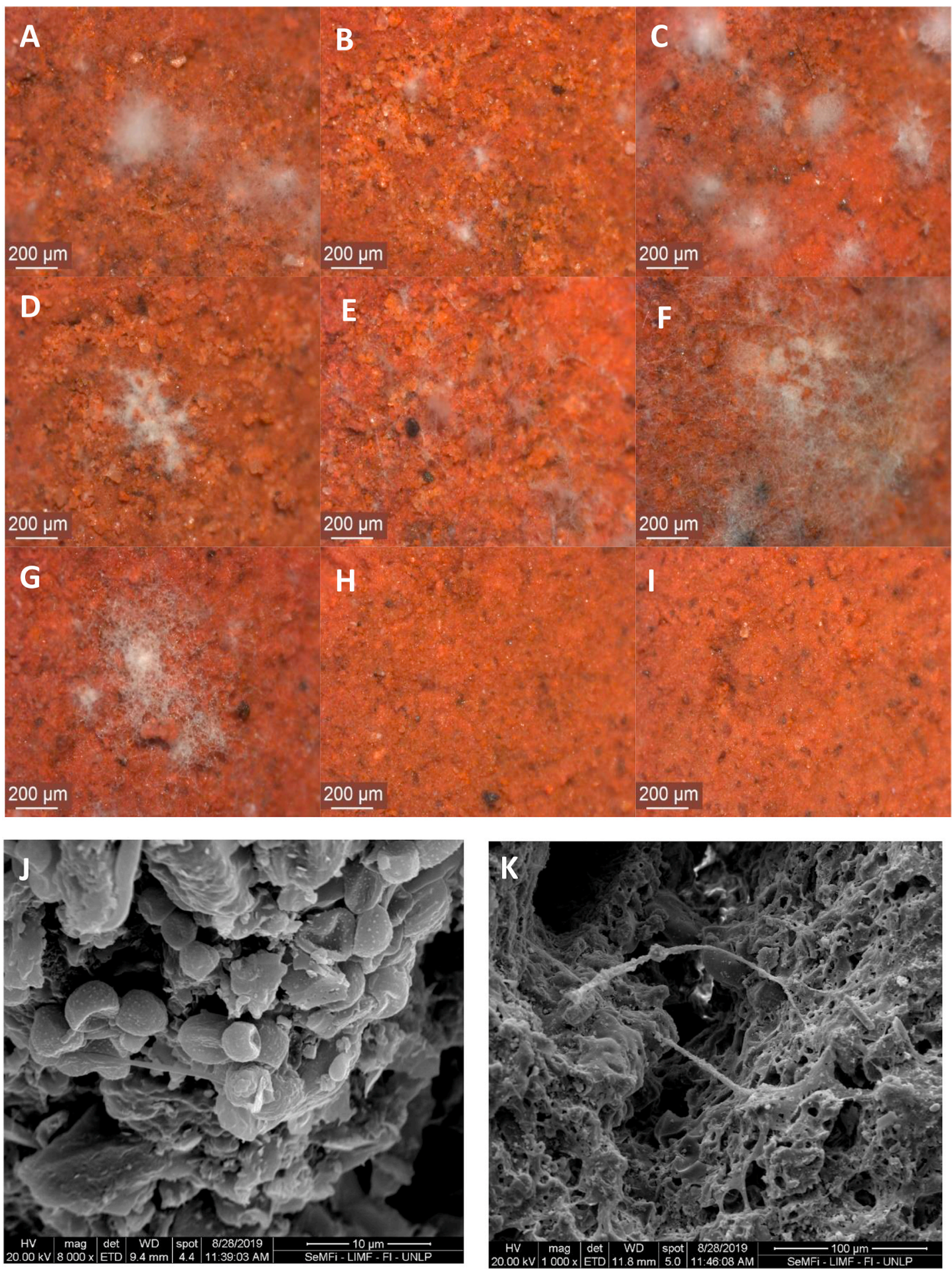

Fig. 5. Bricks inoculated and exposed in the Humidity Chamber. A-I: Stereoscopic microscope images. J and K: SEM micrographs ( $\mathrm{t}=12 \mathrm{months})$. A: E. nigrum, B: Arthrinium sp. 1, C: L. theobromae, D: Arthrinium sp. 2, E: YUSM, F: A. spectabile, G: DUSM 1, H: DUSM 2 and I: Uninoculated brick.

species. Then, it is necessary to protect the monuments from where the species were isolated. This protection can be performed through the application of antifungal coatings on the materials in order to control the fungal deterioration [43].

\subsection{Molecular analysis of most deteriorating fungal strains}

Taking into account the obtained results and the analyses performed above, molecular analysis was carried out on the following strains:
Cladosporium sphaerospermum (100\% apparition relative frequency), Penicillium commune and Aspergillus niger (highest $\mathrm{pH}$ variation in LMM) and finally Lasiodiplodia theobromae as well as Arthothelium spectabile presented the highest brick weight variation values. Accordingly, it was possible to reaffirm the taxonomic identification by molecular techniques. Sequences were uploaded to GenBank database and the access numbers: MN371394, MN371392, MN371276, MN371283 and MT071822 were assigned to $C$. sphaerospermum, $P$. commune, A. niger, L. theobromae and A. spectabile isolates, respectively. 


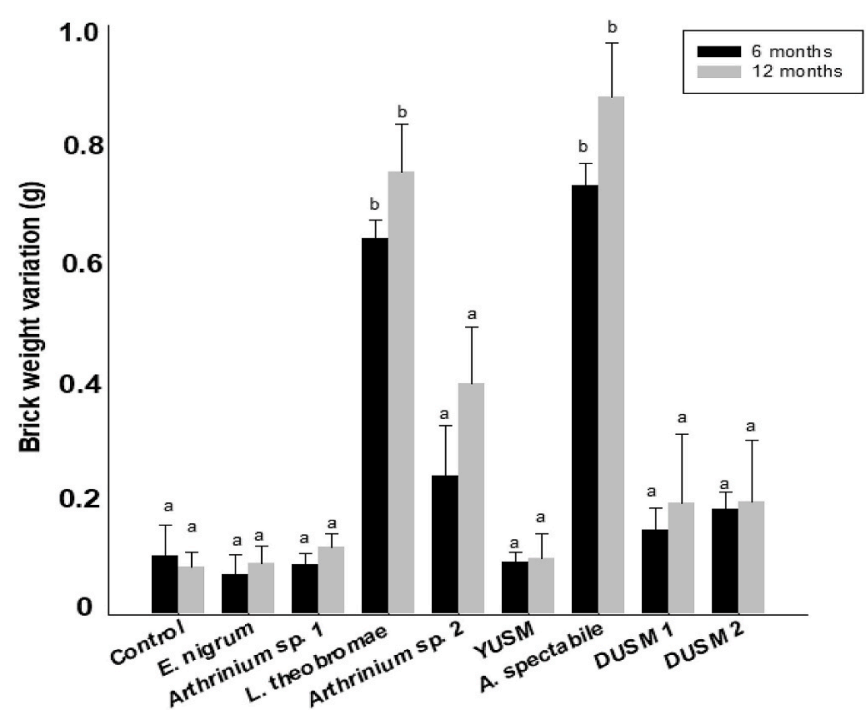

Fig. 6. Loss of weights values in the bricks at different times, different letters on bars indicate difference statistically significant $(\rho \leq 0.05)$ and for Tukey test.
The clustering analysis shows the relationship between the species with higher biodeteriorating activity (Fig. 8). The values listed from left to right next to each cluster node correspond to the bootstrap values performed using 1000 replications, and the branches shown correspond to values $95 \%$, being fungi grouped according to their Family. In particular, $P$. commune and A. niger belong to Aspergillaceae. Nevertheless, $C$. sphaerospermum, $L$. theobromae and A. spectabile are located within Cladosporiaceae, Botryosphaeriaceae and Arthoniaceae, respectively. UPGMA analysis showed consistent clustering of isolates, but the phylogram presented a divergence point where $A$. spectabile and $L$. theobromae did not share a common ancestor with the rest of the species. The optimal tree with the sum of branch length $=1.76794872$ is shown. The tree is drawn to scale, with branch lengths in the same units as those of the evolutionary distances used to infer the phylogenetic tree. All positions with less than $100 \%$ site coverage were eliminated. There was a total of 195 positions in the final dataset.

The results indicate that the study of the mycobiota, which intervenes in the biodeterioration of building materials based on their ecology and deteriorating attributes, can contribute to subsequently carry out studies focused on the protection of brick and concrete. Despite these promising results, further research should be undertaken to research on the fungi in consortium and the effect of competition between the strains. In this sense, it would be interesting to study the combined growth of these strains and their effect on bricks or concrete

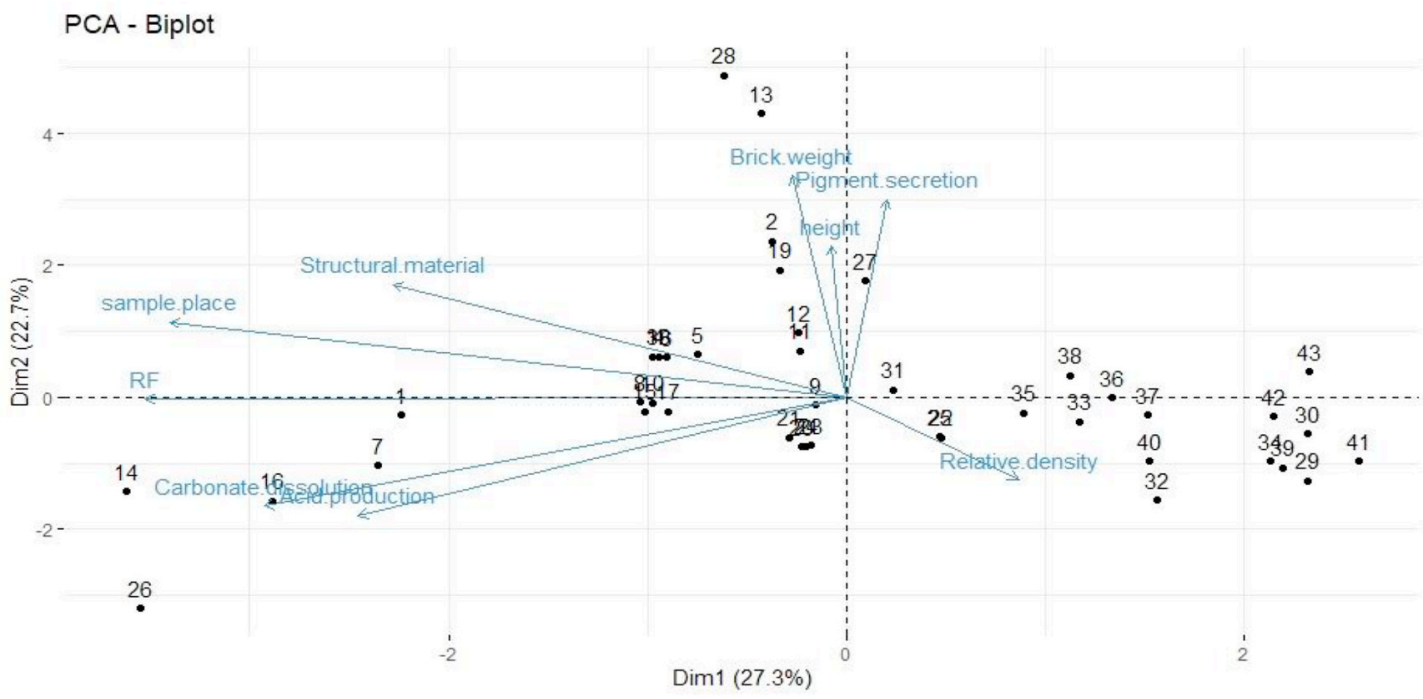

Fig. 7. PCA ordination of fungal isolates (represented as numbers in the figure) according to the variables analyzed.
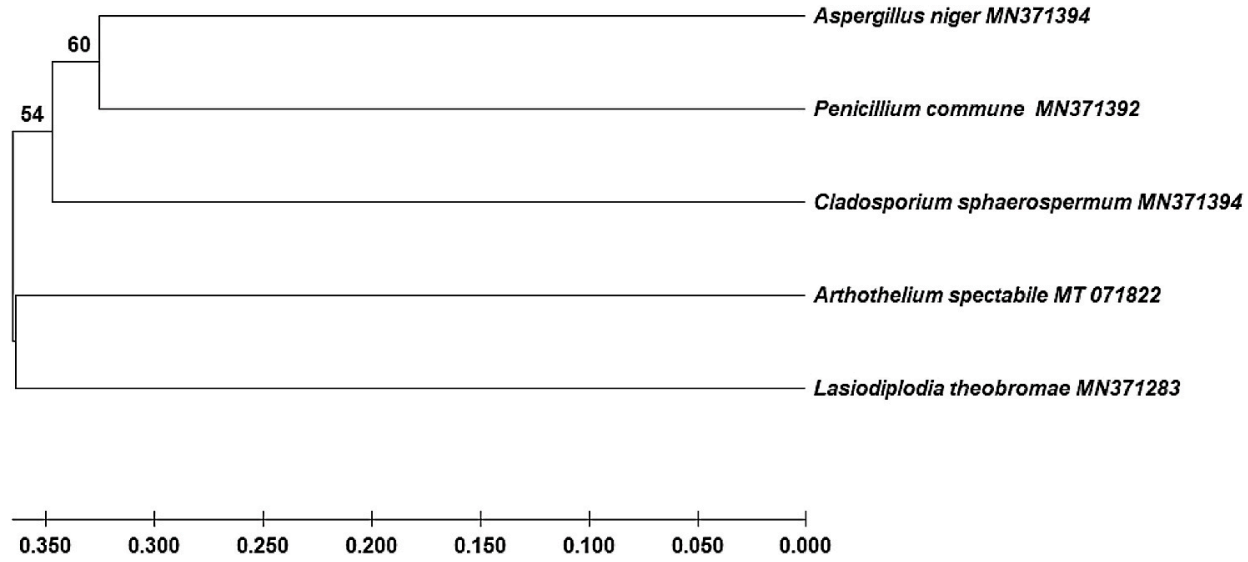

Fig. 8. UPGMA cluster analysis of fungi isolated with greater deteriorating potential. The evolutionary distances were calculated using the p-distance model. The Bootstrap numbers shown on the left (95\%) were obtained using 1000 replicates. The horizontal scale indicates the level of dissimilarity. 
deterioration.

\section{Conclusions}

Through the sampling method and the isolation techniques used, it was possible to study the mycobiota present in facades of two buildings in La Plata (the Cathedral of La Plata and the Experimental Station of the Centro de Investigación y Desarrollo en Tecnología de Pinturas).

The tests performed allowed obtaining the most deteriorating strains: A. niger MN371276, L. theobromae MN371283, C. sphaerospermum MN371394, P. commune MN371392 and A. spectabile MT071822. Molecular method was used to confirm the strains identification and to analyze their evolutionary relationship. In this sense, it is interesting to highlight that the two strains $L$. theobromae and A. spectabile, which resulted older than the rest of the strains from an evolutionary point of view, also produced the highest deteriorating effect on bricks reflected in weight loss after the humidity chamber test.

The research has also shown mycological studies as a tool to obtain information about the culturable species present in the biofilm of building spoilage. In this sense, some of these strains can be used for their adaptability to grow under laboratory conditions in a study that seeks the efficient assessment of new materials with biocidal potentialities, and therefore the improvement of building biodeterioration control.

\section{Author statement}

Lic. Erasmo Gámez-Espinosa: Methodology, Investigation, Writing Original Draft.

Dra. Natalia Bellotti: Conceptualization, Methodology, Resources, Visualization, Project Administration; Writing-Review \& Editing, Supervision, Funding

Acquisition.

Dra. Cecilia Deya: Methodology, Supervision.

Dra. Marta Cabello: Conceptualization, Visualization, Methodology, Supervision.

\section{Declaration of competing interest}

The authors declare that they have no known competing financial interests or personal relationships that could have appeared to influence the work reported in this paper.

\section{Acknowledgment}

Authors are thankful for the essential support to: Consejo Nacional de Investigaciones Científicas y Técnicas (CONICET), Comisión de Investigaciones Científicas de la provincia de Buenos Aires (CICPBA), Agencia Nacional de Promoción Científica y Tecnológica (ANPCyT), Universidad Nacional de La Plata (UNLP) and Astronomical Observatory of La Plata. They also thank to the technical support of the Ing. Pablo Bellotti.

\section{References}

[1] J. Trovão, A. Portugal, F. Soares, D.S. Paiva, N. Mesquita, C. Coelho, A.C. Pinheiro, L. Catarino, F. Gil, I. Tiago, Fungal diversity and distribution across distinct biodeterioration phenomena in limestone walls of the old cathedral of Coimbra, UNESCO World Heritage Site, Int. Biodeterior. Biodegrad. 142 (2019) 91-102, https://doi.org/10.1016/j.ibiod.2019.05.008.

[2] F.L. Guerra, W. Lopes, J.C. Cazarolli, M. Lobato, A.B. Masuero, D.C.C. Dal Molin, F. M. Bento, A. Schrank, M.H. Vainstein, Biodeterioration of mortar coating in historical buildings: microclimatic characterization, material, and fungal community, Build. Environ. 155 (2019) 195-209, https://doi.org/10.1016/j. buildenv.2019.03.017.

[3] B.K. Stefanowski, S.F. Curling, G.A. Ormondroyd, A rapid screening method to determine the susceptibility of bio-based construction and insulation products to mould growth, Int. Biodeterior. Biodegrad. 116 (2017) 124-132, https://doi.org/ 10.1016/j.ibiod.2016.10.025.
[4] M. Fatahinia, A. Zarei-Mahmoudabadi, H. Shokri, H. Ghaymi, Monitoring of mycoflora in outdoor air of different localities of Ahvaz, Iran, J. Mycol. Med. 28 (2018) 87-93, https://doi.org/10.1016/j.mycmed.2017.12.002.

[5] H. Paiva de Carvalho, N. Mesquita, J. Trovão, S. Fernández Rodríguez, A. C. Pinheiro, V. Gomes, A. Alcoforado, F. Gil, A. Portugal, Fungal contamination of paintings and wooden sculptures inside the storage room of a museum: are current norms and reference values adequate? J. Cult. Herit. 34 (2018) 268-276, https:// doi.org/10.1016/j.culher.2018.05.001.

[6] J.A. Gilbert, B. Stephens, Microbiology of the built environment, Nat. Rev. Microbiol. 16 (2018) 661-670, https://doi.org/10.1038/s41579-018-0065-5.

[7] M.L. Coutinho, A.Z. Miller, A. Phillip, J. Mirão, L. Dias, M.A. Rogerio-Candelera, C. Saiz-Jimenez, P.M. Martin-Sanchez, L. Cerqueira-Alves, M.F. Macedo, Biodeterioration of majolica glazed tiles by the fungus Devriesia imbrexigena, Construct. Build. Mater. 212 (2019) 49-56, https://doi.org/10.1016/j. conbuildmat.2019.03.268.

[8] J.-D. Gu, Microbial biofilms, fouling, corrosion, and biodeterioration of materials, in: Handb. Environ. Degrad. Mater, third ed., Elsevier, 2018, pp. 273-298, https:// doi.org/10.1016/B978-0-323-52472-8.00014-9.

[9] S. Gómez de Saravia, P. Battistoni, P. Guiamet, Phototrophic biofilms on exterior brick substrate, Res. Rev. Biosci. 11 (2016) 1-10.

[10] V. Rosato, F. Lloro, L. Traversa, Deterioro biológico de materiales y técnicas para su limpieza y prevención, 1 ed, Laboratorio de Entrenamiento Multidisciplinario para la Investigación Tecnológica, La Plata, 2016.

[11] S.O. Sequeira, M.L. Coutinho, J.C. Lima, A.J.L. Phillips, M.F. Macedo, E.J. Cabrita, 4-MUF-NAG for fungal biomass determination: scope and limitations in the context of biodeterioration studies, J. Cult. Herit. 22 (2016) 992-998, https://doi.org/ 10.1016/j.culher.2016.06.002.

[12] B. Crook, N.C. Burton, Indoor moulds, Sick Building Syndrome and building related illness, Fungal Biol. Rev. 24 (2010) 106-113, https://doi.org/10.1016/j. fbr.2010.05.001.

[13] T. Verdier, M. Coutand, A. Bertron, C. Roques, A review of indoor microbial growth across building materials and sampling and analysis methods, Build. Environ. 80 (2014) 136-149, https://doi.org/10.1016/j.buildenv.2014.05.030.

[14] J.C. Samson, R.A, E.S. Hoekstra, Frisvad, Introduction to Food and Airborne Fungi, seventh ed., CBS, The Netherlands, 2004.

[15] J.I. Pitt, A.D. Hocking, Fungi and Food Spoilage, Springer US, Boston, MA, 2009, https://doi.org/10.1007/978-0-387-92207-2.

[16] R. Smith, Ecology and Field Biology, third ed., Harper and Row, New York, 1980.

[17] P. Esquivel, M. Mangiaterra, G. Giusiano, M.A. Sosa, Anemophilous microfungi in outdoor environments of two cities in Argentinian northeastern, Boletín Micológico. 18 (2003) 21-28, https://doi.org/10.22370/bolmicol.2003.18.0.376.

[18] I. Dimkić Unković, M. Stupar, S. Stanković, J. Vukojević, M. Ljaljević Grbić, Biodegradative potential of fungal isolates from sacral ambient: in vitro study as risk assessment implication for the conservation of wall paintings, PloS One 13 (2018), e0190922, https://doi.org/10.1371/journal.pone.0190922.

[19] M. Anaya, S.F. Borrego, E. Gámez, M. Castro, A. Molina, O. Valdés, Viable fungi in the air of indoor environments of the National Archive of the Republic of Cuba, Aerobiologia (Bologna) 32 (2016) 513-527, https://doi.org/10.1007/s10453-0169429-3.

[20] R.P. George, S. Ramya, D. Ramachandran, U. Kamachi Mudali, Studies on Biodegradation of normal concrete surfaces by fungus Fusarium sp, Cement Concr. Res. 47 (2013) 8-13, https://doi.org/10.1016/j.cemconres.2013.01.010.

[21] D. Vu, M. Groenewald, M. de Vries, T. Gehrmann, B. Stielow, U. Eberhardt, A. AlHatmi, J.Z. Groenewald, G. Cardinali, J. Houbraken, T. Boekhout, P.W. Crous, V. Robert, G.J.M. Verkley, Large-scale generation and analysis of filamentous fungal DNA barcodes boosts coverage for kingdom fungi and reveals thresholds for fungal species and higher taxon delimitation, Stud. Mycol. 92 (2019) 135-154, https://doi.org/10.1016/j.simyco.2018.05.001.

[22] C.L. Schoch, K.A. Seifert, S. Huhndorf, V. Robert, J.L. Spouge, C.A. Levesque, W. Chen, Fungal Barcoding Consortium, Nuclear ribosomal internal transcribed spacer (ITS) region as a universal DNA barcode marker for Fungi, Proc. Natl. Acad. Sci. Unit. States Am. 109 (2012) 6241-6246, https://doi.org/10.1073/ pnas.1117018109.

[23] T.J. White, T. Bruns, S. Lee, J. Taylor, Amplification and direct sequencing of fungal ribosomal RNA genes for phylogenetics, in: M.A. Innis, D.H. Gelfand, J. Shinsky, T.J. White (Eds.), PCR Protoc, Elsevier, New York, 1990, pp. 315-322, https://doi.org/10.1016/B978-0-12-372180-8.50042-1.

[24] E. Gomes, O.L. Pereira, C.C. da Silva, C.B.P. Bento, M.V. de Queiroz, Diversity of endophytic fungi in Glycine max, Microbiol. Res. 181 (2015) 84-92, https://doi. org/10.1016/j.micres.2015.05.010.

[25] S. Kumar, G. Stecher, M. Li, C. Knyaz, K. Tamura, MEGA X: molecular evolutionary genetics analysis across computing platforms, Mol. Biol. Evol. 35 (2018) 1547-1549, https://doi.org/10.1093/molbev/msy096.

[26] A.C. Mallo, L.A. Elíades, D.S. Nitiu, M.C.N. Saparrat, Fungal monitoring of the indoor air of the Museo de La Plata Herbarium, Argentina, Rev. Iberoam. Micol. 34 (2017) 99-105, https://doi.org/10.1016/j.riam.2016.05.003.

[27] M.M. Negrin, M.T. Del Panno, A.E. Ronco, Study of bioaerosols and site influence in the La Plata area (Argentina) using conventional and DNA (fingerprint) based methods, Aerobiologia (Bologna) 23 (2007) 249-258, https://doi.org/10.1007/ s10453-007-9069-8.

[28] P.S. Guiamet, V. Rosato, S.G. de Saravia, A.M. García, D.A. Moreno, Biofouling of crypts of historical and architectural interest at La Plata Cemetery (Argentina), J. Cult. Herit. 13 (2012) 339-344, https://doi.org/10.1016/j.culher.2011.11.002.

[29] A. Hyvarinen, T. Meklin, A. Vepsalainen, A. Nevalainen, Fungi and actinobacteria in moisture-damaged building materials - concentrations and diversity, Int. 
Biodeterior. Biodegrad. 49 (2002) 27-37, https://doi.org/10.1016/S0964-8305 (01)00103-2.

[30] B. Cwalina, Biodeterioration of concrete, brick and other mineral-based building materials, in: Underst. Biocorrosion, Elsevier, 2014, pp. 281-312, https://doi.org/ 10.1533/9781782421252.3.281.

[31] F.A. Wichmann, A. Müller, L.E. Busi, N. Cianni, L. Massolo, U. Schlink, A. Porta, P. D. Sly, Increased asthma and respiratory symptoms in children exposed to petrochemical pollution, J. Allergy Clin. Immunol. 123 (2009) 632-638, https:// doi.org/10.1016/j.jaci.2008.09.052.

[32] M. de la P. Diulio, P. Mercader-Moyano, A.F. Gómez, The influence of the envelope in the preventive conservation of books and paper records. Case study: libraries and archives in La Plata, Argentina, Energy Build. 183 (2019) 727-738, https:// doi.org/10.1016/j.enbuild.2018.11.048.

[33] K.F. Nielsen, G. Holm, L.P. Uttrup, P.A. Nielsen, Mould growth on building materials under low water activities. Influence of humidity and temperature on fungal growth and secondary metabolism, Int. Biodeterior. Biodegrad. 54 (2004) 325-336, https://doi.org/10.1016/j.ibiod.2004.05.002.

[34] N. Makul, Modern sustainable cement and concrete composites: review of current status, challenges and guidelines, Sustain. Mater. Technol. 25 (2020), e00155, https://doi.org/10.1016/j.susmat.2020.e00155.

[35] V.B. Ponizovskaya, N.L. Rebrikova, A.V. Kachalkin, A.B. Antropova, E. N. Bilanenko, V.L. Mokeeva, Micromycetes as colonizers of mineral building materials in historic monuments and museums, Fungal Biol. 123 (2019) 290-306, https://doi.org/10.1016/j.funbio.2019.01.002.
[36] J. Schumacher, A.A. Gorbushina, Light sensing in plant- and rock-associated black fungi, Fungal Biol. 124 (2020) 407-417, https://doi.org/10.1016/j. funbio.2020.01.004.

[37] K.V. Sazanova, S.M. Shchiparev, D.Y. Vlasov, Formation of organic acids by fungi isolated from the surface of stone monuments, Microbiology 83 (2014) 516-522, https://doi.org/10.1134/S002626171405021X.

[38] R.J.B. Cordero, A. Casadevall, Functions of fungal melanin beyond virulence, Fungal Biol. Rev. 31 (2017) 99-112, https://doi.org/10.1016/j.fbr.2016.12.003.

[39] G. Chamilos, T. Akoumianaki, I. Kyrmizi, A. Brakhage, A. Beauvais, J.-P. Latge, Melanin targets LC3-associated phagocytosis (LAP): a novel pathogenetic mechanism in fungal disease, Autophagy 12 (2016) 888-889, https://doi.org/ 10.1080/15548627.2016.1157242.

[40] N. Sathiparan, U. Rumeshkumar, Effect of moisture condition on mechanical behavior of low strength brick masonry, J. Build. Eng. 17 (2018) 23-31, https:// doi.org/10.1016/j.jobe.2018.01.015.

[41] M.L. Coutinho, A.Z. Miller, M.F. Macedo, Biological colonization and biodeterioration of architectural ceramic materials: an overview, J. Cult. Herit. 16 (2015) 759-777, https://doi.org/10.1016/j.culher.2015.01.006.

[42] J.M. Jeschke, W. Gabriel, H. Kokko, r-Strategists/K-Strategists, in: Encycl. Ecol, Elsevier, 2019, pp. 193-201, https://doi.org/10.1016/B978-0-12-4095489.11121-2.

[43] E. Gámez-Espinosa, L. Barberia-Roque, O.F. Obidi, C. Deyá, N. Bellotti, Antifungal applications for nano-additives synthesized with a bio-based approach, Adv. Nat. Sci. Nanosci. Nanotechnol. 11 (2020), 015019, https://doi.org/10.1088/20436254/ab790f. 